\title{
Should we design buildings for lower-probability earthquake motion?
}

\author{
Hing-Ho Tsang
}

Received: 22 March 2011/Accepted: 23 March 2011/Published online: 3 April 2011

(C) The Author(s) 2011. This article is published with open access at Springerlink.com

\begin{abstract}
On February 22, 2011, an earthquake of magnitude 6.3 occurred very near to the city of Christchurch, New Zealand. The consequence came as a shock to many seismologists and earthquake engineers as New Zealand is known as the homeland of modern earthquake-resistant design techniques. After the earthquake, the focus of discussion has been on the collapse of buildings, while few queried the adequacy of design requirements. Importantly, similar "inadequacy" seems to repeat all around the world more frequently than expected. Hence, the question statement in the title concerns not only Christchurch, but anywhere in the world.
\end{abstract}

Keywords Earthquake $\cdot$ Probability $\cdot$ Buildings $\cdot$ Collapse prevention $\cdot$ Design

\section{Collapse prevention limit}

As the global standard of seismic design performance requirements, collapse prevention shall be provided in a 1 in 2,500 year earthquake shaking, which corresponds to a $2 \%$ probability of exceedance in the notional design life of 50 years. In the Structural Design Actions Part 5: Earthquake Actions-New Zealand, NZS 1170.5:2004 (Standards New Zealand 2004a), a hazard factor Z, representing the 1 in 500 year earthquake ground shaking in the horizontal direction, is assigned for every part of the country and shown in the format of a contour map. A factor of 1.8 is used to scale the hazard factor $\mathrm{Z}$ to the ultimate limit state of collapse prevention. Such design philosophy, with minor deviations, has generally been adopted in other parts of the world.

The Z-factor contour map was developed by the Institute of Geological and Nuclear Sciences (re-named as GNS Science in 2006) using an internationally recognized earthquake hazard assessment procedure (Stirling et al. 2002), tailor-made for the seismotectonic setting of New Zealand. For Christchurch, the Z-value is $22 \% \mathrm{~g}$ (g is the acceleration due to gravity) and the corresponding collapse prevention limit would be at $40 \% \mathrm{~g}$. This is

H.-H. Tsang $(\bowtie)$

Department of Civil Engineering, The University of Hong Kong, Pokfulam Road, Hong Kong e-mail: tsanghh@hku.hk 
the 1 in 2,500 year peak ground acceleration (PGA) motion in the horizontal direction. The associated maximum structural acceleration (SA) response of low-to-medium-rise buildings on very soft soils (that amplify ground motions) would be $120 \% \mathrm{~g}$. In simple terms, buildings in Christchurch should be capable of sustaining a horizontal loading of $120 \%$ of its own weight. Meanwhile, a ratio of 0.7 between vertical and horizontal motions has been adopted in the New Zealand standard. Thus, the corresponding vertical motions for collapse limit state become $28 \% \mathrm{~g}$ for PGA and $84 \% \mathrm{~g}$ for SA.

\section{Shaking intensity in Christchurch}

Strong-motion data recorded by GNS Science have been processed and analyzed by the United States Geological Survey (USGS, http://earthquake.usgs.gov/earthquakes/), from which the data recorded at six stations within Christchurch (including suburbs) have been obtained for the following illustration. Recorded peak motion values exceeding the design values at collapse limits are shown in bold fonts in Table 1. It is shown that the recorded motions are on average 50\% higher than the design limits for collapse prevention. I have also generated contour maps (prepared by The Generic Mapping Tools, http://www. soest.hawaii.edu/gmt/) that show the spatial distribution of shaking in Christchurch and the surrounding region (Fig. 1). It is shown that a large area was shaken more severely than the design collapse limits. Thus, the chance of survival of buildings in the region could only count on various intrinsic conservatisms embodied in structural design assumptions.

Some may attribute the strong motions to uncertainties in the ground motion estimates and in the characterization of the potential earthquake sources. In my opinion, the Z-factor contour map of New Zealand should be regarded as a reliable reference, as it reflects the state-of-the-art knowledge and has incorporated various sources of uncertainties. Thus, the question to be posed is "shall we design our infrastructure to resist earthquake motions with a probability of exceedance lower than $2 \%$ in 50 years?" It is the perception of earthquake probability of the general public and that of the policy makers that counts. This is of particular concern in regions that are subject to the underrated risk of low-probability high-consequence earthquakes.

Table 1 Summary of shaking level recorded in Christchurch

\begin{tabular}{|c|c|c|c|c|c|c|}
\hline \multirow[t]{2}{*}{ Station Code } & \multirow[t]{2}{*}{ Latitude } & \multirow[t]{2}{*}{ Longitude } & \multicolumn{2}{|c|}{ Maximum horizontal motion } & \multicolumn{2}{|c|}{ Maximum vertical motion } \\
\hline & & & $\mathrm{PGA}^{\mathrm{a}}(\% \mathrm{~g})$ & $\mathrm{SA}^{\mathrm{b}}(\% \mathrm{~g})$ & $\mathrm{PGA}^{\mathrm{a}}(\% \mathrm{~g})$ & $\mathrm{SA}^{\mathrm{b}}(\% \mathrm{~g})$ \\
\hline $\mathrm{CCCC}$ & -43.540 & 172.647 & 48 & 185 & 69 & 135 \\
\hline $\mathrm{CHHC}$ & -43.538 & 172.627 & 36 & 263 & 51 & 81 \\
\hline HPSC & -43.503 & 172.702 & 24 & 82 & 86 & 106 \\
\hline PRPC & -43.528 & 172.683 & 66 & 184 & 163 & 396 \\
\hline RHSC & -43.538 & 172.564 & 29 & 230 & 19 & 44 \\
\hline SHLC & -43.507 & 172.663 & 34 & 251 & 50 & 76 \\
\hline
\end{tabular}

\footnotetext{
${ }^{a}$ PGA: peak ground acceleration

b SA: maximum structural acceleration response of low-to-medium-rise buildings
} 

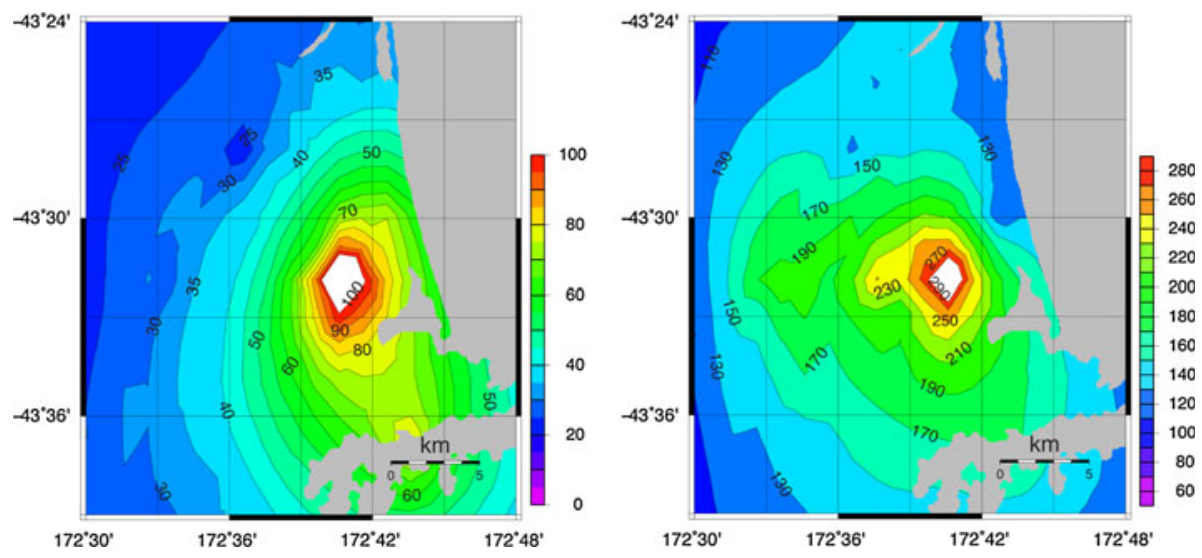

Fig. 1 Actual shaking in Christchurch. Contour maps depicting the shaking level, (left) peak ground acceleration (in unit of \%g), and (right) maximum structural acceleration response of low-to-medium-rise buildings (in unit of $\% \mathrm{~g}$ ), in Christchurch and the surrounding region. A large area was shaken more severely than the design collapse limits

\section{Unexpected?}

One may want to know whether such situation is an isolated case, which rarely occurs. In fact, similar situations have been repeated in other countries in the recent past. Two cases are cited in below.

Before 1995, Kobe, Japan, had been considered as having very low risks of being affected by a damaging earthquake. On January 17, 1995, a M6.8 earthquake struck Kobe causing a death toll of 6,000. Some 56,000 buildings were totally destroyed, and 110,000 buildings were severely damaged. The recorded horizontal PGA was 50-90\%g, which was on average $100 \%$ greater than the design values (Chandler 1997).

On May 12, 2008, a M8 earthquake occurred in Sichuan Province of China depriving tens of thousands of lives and destroying homes of millions of people. For regions with high death tolls (which include Deyang, Mianyang, Ngawa, Guangyuan), the design PGA for collapse limit state was $12.6 \% \mathrm{~g}$ (Ministry of Construction of the People's Republic of China 2001). The immediate epicentral areas (including Wenchuan and Dujiangyan) and other severely affected regions (such as Beichuan, Shifang, Mianzhu) had a collapse limit of $22.5 \% \mathrm{~g}$. Noted that greater than $45 \% \mathrm{~g}$ of the PGA was commonly recorded in the aforementioned areas.

\section{Smaller collapse margin?}

The Christchurch, Kobe, and Wenchuan earthquake motions could be considered as very low-probability cases and their potentials had likely been ignored in the seismic design for collapse prevention. However, nobody could deny that the consequences are really unbearable to any society nowadays. These events lead us to doubt whether the stipulated level of earthquake protection of buildings is adequate or not.

Buildings should have a small margin against collapses when subjected to the most severe earthquake shaking which is considered possible, while the 1 in 2,500-year motion is just the maximum ground motion "considered" by engineers. This poses a scientific 
question that "how much is the difference between such motion and the more severe ground motion?" According to the Supplement to NZS 1170.5:2004 (Standards New Zealand 2004b), the 1 in 10,000-year motion is approximately 40-50\% larger than the 1 in 2,500-year motion. As the recorded motions shown in Table 1 are on average $50 \%$ higher than the collapse limits ( 1 in 2,500-year motions), the shaking at Christchurch was probably a 1 in 10,000-year motion.

The difference could be larger for regions of low-to-moderate seismicity, in which the ground motion amplitudes increase more rapidly as probability decreases. A hazard study for Hong Kong shows that the 1 in 10,000-year motion estimated on rock sites is around $80 \%$ larger than the 1 in 2,500 year one (Tsang and Chandler 2006; Tsang et al. (2010) in press).

\section{Perception of earthquake probability}

In fact, the collapse prevention limit should be taken as the 1 in 2,500 year risk level for a particular building, of which the property owner has to bear throughout the whole design life. However, the associated earthquake itself has a much higher probability of occurrence. This is the sparse spatial distribution of earthquake events that lowers the probability of damaging ground motions.

Put this argument in the New Zealand context as example: assuming there were 20 earthquakes with $M \geq 6.3$ occurring all over New Zealand in the last 100 years, the annual probability of occurrence of such event is 0.2 (which can be considered as a very frequent event). Based on the total area of New Zealand being around $268,000 \mathrm{~km}^{2}$, the probability of such $\mathrm{M} \geq 6.3$ event occurring within $12 \mathrm{~km}$ of Christchurch (as of the one in February 2011 ) is 0.0017 (i.e. the area ratio). Considering further the relative seismicity within New Zealand (with hazard factor $\mathrm{Z}$ ranging from $13 \% \mathrm{~g}$ to $60 \% \mathrm{~g}$ ), the relative likelihood of occurrence of such an event at a location with a relatively lower seismicity $(Z=22 \% \mathrm{~g})$ would be approximately 0.6 . Taking into account ground motion uncertainties, there is a 0.5 chance of exceeding the median prediction (i.e., target ground motion). Hence, the total probability of exceeding the target ground motion would be (0.2) (0.0017) (0.6) $(0.5)=0.0001$ (i.e., 1 in 10,000 year). This explains why a "very frequent" M6.3 earthquake would become a "very low-probability" motion.

The concept can be demonstrated in another simple way. If a damaging ground motion has a probability of exceedance of $0.5 \%$ in 50 years ( 1 in 10,000 year) being within a particular city of a country, this seems to be a very rare motion that people living in that city tend to ignore. However, the probability of having such a rare ground motion in all 50 cities of that country (assuming similar seismotectonic environment) will become $22 \%$ in 50 years in collective terms. Is that $0.5 \%$ still a small number that policy makers can ignore?

\section{Call for action}

For a developing country, it may be difficult to stipulate a higher level of protection in design codes. However, for a developed country or city, where resources are comparatively abundant, why do not we provide a higher level of protection for our community? Designing for the 1 in 10,000 year earthquake motion may elevate the building costs by merely a few per cent, which is absolutely acceptable if compared with potential 
post-earthquake repair or reinstatement costs. Such slight increase in the costs can reduce the collapse margin, and the associated loss of lives, from 2 to $0.5 \%$ in a design life of 50 years.

Earthquake shaking exceeding design collapse limits occurs more frequently than expected; it is our perception of earthquake probability that counts. Action is required sooner rather than later to prevent disasters to repeat in other earthquake-prone cities in future.

Open Access This article is distributed under the terms of the Creative Commons Attribution Noncommercial License which permits any noncommercial use, distribution, and reproduction in any medium, provided the original author(s) and source are credited.

\section{References}

Chandler AM (1997) Engineering design lessons from Kobe. Nature 387:227-229

Code for Seismic Design of Buildings. GB 50011-2001 (2001) Ministry of Construction of the People's Republic of China, China Architecture and Building Press, Beijing, China

Stirling MW, McVerry GH, Berryman KR (2002) A new seismic hazard model for New Zealand. Bull Seismol Soc Am 92:1878-1903

Tsang HH, Chandler AM (2006) Site-specific probabilistic seismic-hazard assessment: direct amplitudebased approach. Bull Seismol Soc Am 96:392-403

Tsang HH, Yaghmaei-Sabegh S, Anbazhagan P, Sheikh MN (2010) A checking method for probabilistic seismic-hazard assessment: case studies on three cities. Natural Hazards [Accessible online: 03 November 2010]

Structural Design Actions Part 5: Earthquake Actions-New Zealand NZS 1170.5:2004 (2004a) Standards New Zealand, Wellington, New Zealand

Structural Design Actions Part 5: Earthquake Actions-New Zealand Commentary (Supplement to NZS 1170.5:2004). NZS 1170.5 Supp 1: 2004 (2004b) Standards New Zealand, Wellington, New Zealand 